\title{
A Opinião dos Turistas de Negócios sobre a Imagem da Cidade de São Paulo ${ }^{1}$
}

\author{
Business Tourists Opinion of São Paulo City Image
}

\author{
José Afonso Mazzon ${ }^{2}$ \\ Luis Alberto Noriega Vera ${ }^{3}$
}

\begin{abstract}
Resumo
O artigo apresenta a análise descritiva dos principais resultados obtidos em pesquisa de campo realizada entre a segunda quinzena de junho e primeira de julho do ano de 2006 nos dois aeroportos da cidade de São Paulo. A pesquisa teve como público alvo os turistas de negócios que visitam a cidade. A amostra foi escolhida intencionalmente e o critério de estratificação foi o local de residência permanente dos turistas. O principal objetivo da pesquisa foi aprimorar o entendimento sobre a avaliação da imagem de um destino turístico. Foi proposto um modelo conceitual a partir do referencial teórico sobre comportamento do consumidor existente nas áreas de turismo e marketing. Os resultados apontam que o perfil dos turistas é consistente com estudos anteriores e a imagem da cidade consolidada como destino de negócios. Em adição é destacada a qualidade dos serviços consumidos, a satisfação e a intenção do turista de retornar e indicar o destino a parentes e amigos.
\end{abstract}

Palavras-chave: destino turístico; turista de negócios; avaliação de imagem; qualidade; lealdade.

\begin{abstract}
This article presents the descriptive analysis of the main results of a survey held from June $15^{\text {th }}$ through July $15^{\text {th }} 2006$ in the two São Paulo City airports. The survey targeted business tourists visiting the city. It was used an intentional sample and the stratification parameter was tourists' place of permanent residence. The main objective was to enhance the knowledge on tourism destination image evaluation. A conceptual model was proposed based on tourism and marketing literature consumer behavior theoretical background. The results obtained pointed out that tourist profile are consistent with prior studies and the consolidated city image as a business destination. It is also highlighted its service quality, satisfaction and tourist's intention to return or indicate the destination to relatives and friends.
\end{abstract}

Keywords: tourism destination; business tourist; image evaluation; quality; loyalty.

\footnotetext{
${ }^{1}$ A pesquisa de imagem de destinos turísticos contou com a colaboração da FAPESP e SP Turis - São Paulo Turismo.

${ }^{2}$ Economista pela FAAP. Mestre e Doutor em Administração pela FEA-USP. Pós-doutor pela Conservatoire Nationl Des Arts et Métiers, em Paris - França. Professor dos cursos de Graduação e Pós-Graduação na área de Marketing do Departamento de Administração da FEA-USP. E-mail: jamazzon@usp.br

${ }^{3}$ Economista pela UFPR. Mestre em Administração pela FEA-USP. Doutor em Engenharia de Transportes pela EPUSP. Atualmente, participa do programa de pós-doutorado do Departamento de Administração da FEA-USP. E-mail: lalberto@usp.br
} 


\section{Introdução}

A relação entre o destino turístico e a sua imagem, como um dos principais elementos de atração de turistas, apresenta certa complexidade (JENKINS, 1999; GALLARZA et al., 2002; ECHTNER e RITCHIE, 2003). A diversidade de estudos existentes tem revelado a relação entre a imagem do visitante e a do destino visitado (SIRGY e SU, 2000), o seu posicionamento e a reação afetiva (PIKE e RYAN, 2004), e a satisfação em relação à infraestrutura, serviços e produtos disponíveis para compra (HEUNG e CHENG, 2000; JENSEN, 2004; PETRICK, 2004). Poucos estudos têm abordado, de maneira integrada, as inter-relações entre qualidade, satisfação, imagem e intenção de retornar ao destino turístico por parte do turista (BIGNÉ et al., 2001; LEE, 2001; RODRIGUES, 2004; CHI, 2005). A escassa produção sobre o tema é uma oportunidade de melhoria do arcabouço conceitual para entendimento da percepção dos turistas sobre a imagem do destino e dos elementos que influenciam essa percepção.

Do ponto de vista do planejamento turístico, além do inventário da infra-estrutura turística existente num determinado destino, torna-se necessário conhecer a opinião do visitante do destino. O julgamento emitido pelos turistas em relação à sua experiência apresenta dois tipos de processos, um cognitivo/perceptivo e o outro emocional. Baseado nesses dois processos, o julgamento da imagem de um destino é influenciado por aspectos antecedentes, ou atitudes, e conseqüências de caráter comportamental.

Embora a cidade de São Paulo apresente uma diversidade de atrativos turísticos, considera-se importante entender a opinião dos seus principais clientes, os turistas de negócios. O seu comportamento é um balizador da oferta de produtos e serviços existentes que possam satisfazer suas necessidades. Em adição, considera-se que, quando satisfeitos, podem compartilhar a sua experiência com amigos e parentes (RIDDLE, 1999).

Considerando esses aspectos, o objetivo do presente estudo é aprimorar o entendimento sobre a avaliação da imagem de um destino turístico, considerando elementos que retratem as expectativas, desempenho, atitude, intenção e comportamento futuro, tais como qualidade, satisfação e lealdade dos turistas em relação ao destino. Para tal fim é proposto um modelo conceitual baseado nas teorias desenvolvidas nas áreas de turismo e marketing, cuja principal premissa é a imagem servir de filtro entre a avaliação do desempenho do destino turístico e a 
intenção do turista de manter uma relação duradoura com o mesmo (BALOGLU e MCCLEARY, 1999; GALLARZA et al., 2001).

\section{Embasamento Teórico}

Os estudos sobre a imagem de um destino turístico datam da década de 70 do século passado (JENKINS, 1999; ETCHNER e RITCHIE, 2003). A maior parte desses estudos tem usado um mapa de importância-desempenho para avaliar as dimensões funcional e afetiva percebidas pelos turistas (CALDWELL e FREIRE, 2004). Alguns estudos apontam a existência de somente a existência de dimensões funcionais no caso de cidades (BRAMWELL e RAWDING, 1996) e um misto dessas duas dimensões em estudos da imagem de um país (O’LEARY e DEEGAN, 2005). Mais recentemente têm surgido estudos que analisam o conjunto de relações causais entre construtos que melhoram a avaliação de um destino turístico. Neles é observada a influência de dois paradigmas: o da desconfirmação das expectativas e o do desempenho. No primeiro, a imagem pré-definida sobre o destino turístico afeta a percepção do turista, tanto em termos de qualidade do destino, como da sua satisfação, o que, consequentemente, afetará a sua intenção de retornar. (BIGNÉ et al., 2001; LEE, 2001; CHI, 2005). O segundo carece de referências na área de turismo e vem sendo apontado na literatura de marketing como sendo a imagem a nova atitude que os consumidores têm após ter passado pela experiência de consumo (JOHNSON et al., 2001).

O modelo da figura 1 mostra as inter-relações que afetam a percepção da imagem do destino turístico e ensejam o comportamento leal que um turista pode adotar. É importante frisar que as inter-relações entre os construtos apresentados revelam efeitos diretos e indiretos. A maior parte dos estudos tem avaliado a relação entre qualidade $\rightarrow$ satisfação $\rightarrow$ lealdade (OLIVER, 1980; TAYLOR e BAKER, 1994; FORNELL et al., 1996; ANDREASSEN e LINDESTAD, 1998; JOHNSON et al., 2001; BAPTISTA, 2005; CHI, 2005). Nessa relação, a satisfação seria o principal antecedente da lealdade e a qualidade teria um impacto indireto. Por outro lado, a relação satisfação $\rightarrow$ imagem $\rightarrow$ lealdade tem sido usada por um limitado número de estudos na área de turismo, pois ainda impera o paradigma da desconfirmação de expectativas na análise da intencionalidade (ANDREASSEN e LINDESTAD, 1998; BIGNÉ et al., 2001; LEE, 2001; LEE, 2003; CHI, 2005). Nessa relação, a imagem prévia se modifica após experiência, formando uma nova atitude (JOHNSON et al., 2001). 


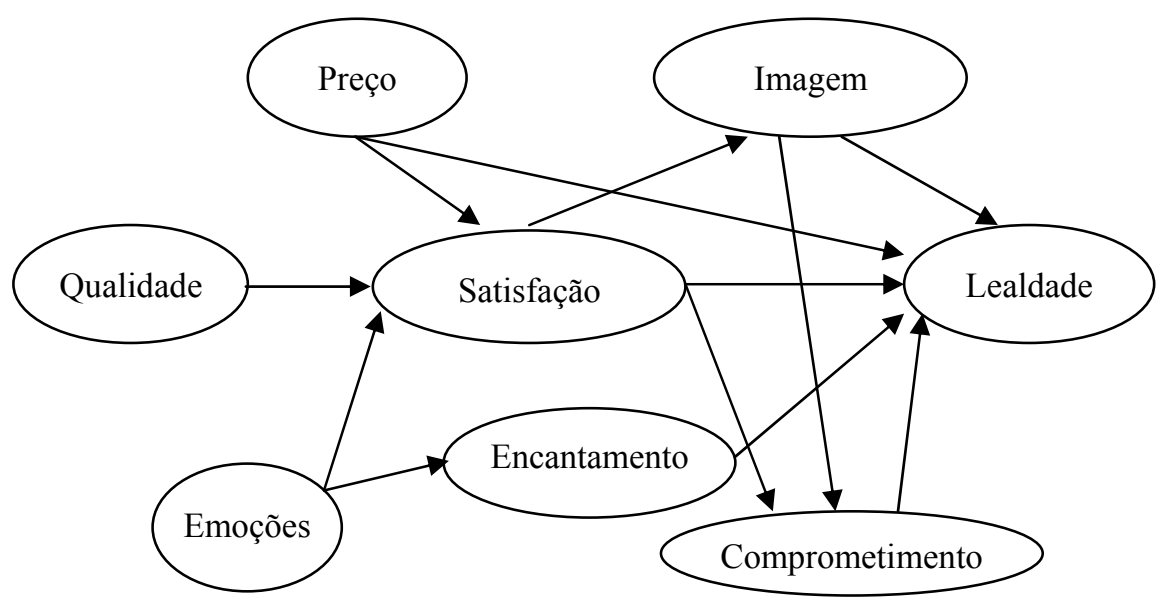

Figura 1: Modelo Conceitual dos Fatores Determinantes da Imagem de um Destino Turístico Fonte: Desenvolvido pelos autores

Finalmente, a relação Satisfação $\rightarrow$ Comprometimento $\rightarrow$ Lealdade tem sido usada em estudos de destino turísticos, nos quais é destacada a satisfação como principal antecedente do comprometimento (IWASAKI e HAVITZ, 1998; LEE, 2001) e o envolvimento como principal antecedente da satisfação (LEE, 2003). Também têm sido apontadas outras duas relações: satisfação $\rightarrow$ lealdade (BIGNÉ et al., 2001, CHI, 2005) e comprometimento $\rightarrow$ lealdade (LEE, 2001), as quais confirmam a importância da satisfação e comprometimento sobre a formação da lealdade dos turistas, quanto à indicação ou retorno ao destino turístico.

Com o intuito de aprimorar os modelos estruturais testados na literatura de marketing turístico (BIGNÉ et al., 2001; LEE, 2001; LEE, 2003; CHI, 2005), outros construtos, como encantamento, emoções e imagem, ainda carecem de validação empírica na área de turismo. No caso das emoções, alguns estudos o apontam como antecedente da satisfação (FARIAS, 1998) e do encantamento (OLIVER et al., 1997). A relação entre imagem e comprometimento, estudada em pesquisas de marca (FOURNIER, 1998; AAKER et al., 2004), considera que esses dois construtos fortalecem a relação entre turistas e destinos turísticos, pela existência de atitude, valores, normas sociais, auto-imagem e fatores situacionais que influenciam o envolvimento do turista e, conseqüentemente, a sua lealdade (IWASAKI e HAVITZ, 1998; SIRGY e SU, 2000; LEE, 2001). 
Para entender as inter-relações entre os construtos do modelo da figura 1 é necessário definir a natureza dos mesmos. A natureza dos construtos possibilita a identificação de dimensões para definir os elementos de caráter racional e afetivo que influenciam as avaliações realizadas pelos indivíduos em relação a um objeto.

Em relação à qualidade, considera-se fundamental identificar as suas dimensões. Na literatura existente, a qualidade pode ser avaliada de forma genérica (técnicas, funcionais e físicas GRÖNROOS, 1990; BITNER, 1992) ou específica para cada produto ou serviço (PARASURANAM, 1988; BRADY e CRONIN, 2001; BAPTISTA, 2005). As pesquisas de destinos turísticos não têm sido a exceção, sendo também diferentes os resultados alcançados (LEE, 2003; MARTÍNEZ-TUR et al., 1996; BIGNÉ et al., 2001). Diante da necessidade de avaliar o desempenho do destino turístico, a identificação das diferentes dimensões é consistente com estudos sobre qualidade e simultaneidade das inter-relações com outros construtos (ZEITHAML et al., 1993; PARASURAMAN et al., 1994; TAYLOR e BAKER, 1994).

Ao definir as dimensões da qualidade de um destino também é considerada a consistência entre ela e a satisfação. A literatura de marketing aponta que somente a satisfação provoca uma mudança de atitude em relação ao produto ou serviço, pois somente determinadas dimensões da qualidade influenciarão a percepção dos indivíduos quanto a sua satisfação em relação a um objeto (BOLTON e DREW, 1991; FORNELL e JOHNSON, 1993). O consumidor avalia a sua satisfação fazendo uma comparação entre as conseqüências esperadas de consumo, benefícios e custos percebidos e interações existentes entre o consumidor e o prestador de serviço após a experiência (CHURCHILL e SURPRENANT, 1982; WOODSIDE et al., 1989; CRONIN e TAYLOR, 1992). Este aspecto possibilita a identificação de aspectos perceptivos e emotivos que afetam seu nível de satisfação.

Consistentemente com estudos anteriores, ao incluir a satisfação na avaliação do desempenho do destino turístico procura-se diferenciar os dois processos de avaliação, da qualidade por um lado e a satisfação por outro (BIGNÉ et al., 2001). Neste estudo se considera que os componentes do destino serão avaliados a partir de dimensões da qualidade, geral e específicas, e o seu impacto na satisfação geral do turista em relação a ele.

Outra relação identificada no modelo mostra o efeito isolado do preço quanto à percepção dos turistas sobre a satisfação $\rightarrow$ imagem de um destino e a sua lealdade. O preço é considerado o 
sacrifício necessário que o consumidor faz para conseguir o produto ou serviço que ele precisa e influencia a sua percepção em relação á qualidade que ele recebe pelo serviço que ele consome (ENGEL et al., 2000), sua satisfação e lealdade (FORNELL et al., 1996; BEI e CHIAO, 2001; JOHNSON et al., 2001). Estudos de turismo apontam que o preço é mais importante entre turistas que visitam um destino pela primeira vez (PETRICK, 2004); contudo, a literatura de marketing aponta que a intensidade da relação preço-satisfação ou preço-lealdade dependerá da complexidade que o serviço apresentar (LIVESEY, 1978); isto é, quanto menos complexo, melhor a percepção e impacto do preço sobre a satisfação e lealdade. No segmento de turismo de negócios o preço dos serviços terá influenciará a percepção do cliente, empresa em que o turista de negócios trabalha, e pouco impacto no consumidor, o próprio turista de negócios (SWARBROOKE e HORNER, 2002).

Em relação ao impacto das emoções sobre os demais construtos, a literatura consultada aponta que a visita ao destino turístico tem efeito favorável entre turistas que retornam, enfatizando diferentes emoções produzidas pelos atrativos que ele possui (PIKE e RYAN, 2004). O turista que apresentar um apego ao destino avalia melhor a sua experiência nele, pois são incluídos determinados tipos de resposta de caráter emocional, tais como encantamento, contentamento, prazer e surpresa (RUSSELL, 1980; IZARD, 1991), o que é um indicador da satisfação do turista em relação aos serviços prestados (FARIAS, 1998) e a sua intenção de retornar ao destino (LEE, 2003)

Um dos construtos de natureza afetiva, que faz parte da estrutura afetiva de Russell (1980), é o encantamento. Ele é um sentimento derivado de uma desconfirmação imprevista que causa surpresa positiva (OLIVER et al., 1997), a qual, considerando a necessidade de se obter uma relação causal forte e duradoura, deverá representar uma reação afetiva mais estável (KUMAR et al., 2001). Ele também depende da natureza do estímulo e da intensidade da emoção (DERBAIX \& PHAM, 1991). Pela natureza afetiva que os diferentes construtos usados no modelo apresentam, tais como satisfação, imagem, comprometimento e lealdade, ao incluir o construto encantamento procura-se identificar o efeito direto que ele possa ter sobre a lealdade. Embora não usado como antecedente da lealdade de um destino turístico em estudos anteriores (BIGNÉ et al. 2001; LEE, 2003; CHI, 2005), considera-se que no caso do destino turístico o encantamento poderá revelar reações afetivas que tem significância pessoal (WESTBROOK, 1987), afetando a satisfação global e consequentemente a lealdade (OLIVER et al., 1997; LEE, 2003). 
Afora os antecedentes atitudinais, tais como satisfação, encantamento e qualidade, um dos construtos que surge como conseqüência da mudança de atitude em relação ao um objeto é o comprometimento. Este conceito, associado a uma intenção, apresenta fundamentação econômica, pois os indivíduos engajam-se numa avaliação dos benefícios recebidos; e psicológica, considerando as crenças em relação ao que é certo e importante na relação entre duas partes (BROWN et al., 1995; BENDAPUDI e BERRY, 1997; BAPTISTA, 2005). A natureza cognitivo-perceptiva e emocional deste construto também gera uma relação coerente entre satisfação e intenção pós-compra (GEVA e GOLDMAN, 1991).

Nos estudos existentes sobre destinos turísticos considera-se que o comprometimento é um construto multidimensional dividido em: comprometimento psicológico, calculativo (IWASAKI e HAVITZ, 1998; JONHSON et al., 2001; LEE, 2001; LEE, 2003) e de resistência à mudança (IWASAKI e HAVITZ, 1998). A influência exercida é o resultado de uma seqüência de processos envolvimento $\rightarrow$ comprometimento psicológico $\rightarrow$ resistência à mudança (IWASAKI e HAVITZ, 1998; LEE, 2001). Diante da existência da relação entre satisfação, imagem e comprometimento, este último passa a ser considerado um mediador entre a atitude dos indivíduos e o seu efetivo comportamento, sendo a intensidade do comprometimento um aspecto indicador da propensão do indivíduo de agir consistentemente em relação à sua atitude.

Quanto ao construto imagem, ele é considerado a atitude resultante da percepção de um objeto, agrupando as crenças e /ou o entendimento da realidade, sendo considerado um guia para o comportamento dos indivíduos (NORMANN, 1984). Nas inter-relações representadas no modelo da figura 1 considera-se que a imagem é um mediador entre qualidade, satisfação e a lealdade, pois ela representa as expectativas pós-consumo, no caso da qualidade e satisfação (JOHNSON et al., 2001), ou a atitude do indivíduo em relação a suas futuras intenções de consumo (lealdade - KELLER, 1993).

A literatura de marketing turístico aponta seu papel como elemento fortalecedor das relações com os visitantes (AHMED, 1991; FYALL et al., 2003). A sua avaliação poderá representar uma oportunidade para definir estratégias de fortalecimento das relações com os turistas, pois ao processar as informações recebidas e avaliar a experiência vivenciada, o turista modifica a imagem induzida (expectativas), transformando-a numa imagem orgânica (atitude), que apresenta forte relação com a intenção de retornar ao destino entre turistas que já o visitaram (AHMED, 1991). 
Finalmente, a lealdade é "um comprometimento acentuado por parte do consumidor" para voltar a consumir um determinado serviço (OLIVER, 1999). A partir de um processo cognitivo o indivíduo passa a definir estratégias, sopesar informações e identificar a importância dos atributos (AUH e JOHNSON, 2005). Na literatura de marketing são identificadas 4 fases: cognitiva, afetiva, conativa e ação (OLIVER, 1999). A cognitiva e afetiva tem sido consideradas um tipo de atitude leal (OPPERMANN, 2000; LEE, 2001; LEE, 2003). Outros tipos de lealdade, a conativa e a ação, têm sido negligenciados na literatura turística, pois se acredita na dificuldade de mensurar o desejo do turista de se comprometer com um determinado destino (OPPERMANN, 2000; BIGNÉ, 2001, CHI, 2005).

Diante do atual estágio das pesquisas sobre destinos turísticos que mostrem numa única estrutura a relação entre os diferentes construtos, a seguir são apresentados os principais resultados obtidos na pesquisa de campo a partir de indicadores de inferência estatística.

\section{Análise dos Dados Coletados}

\subsection{A pesquisa de campo}

A pesquisa de campo foi realizada entre a $2^{\circ}$ quinzena de junho e $1^{\circ}$ quinzena de julho de 2006 no Aeroporto Internacional de São Paulo/Guarulhos - Governador André Franco Montoro, e no Aeroporto Internacional de Congonhas/São Paulo. A população alvo foi o turista de negócios. Considerando o caráter exploratório deste estudo, foi definida uma amostra por conveniência (MARCONI e LAKATOS, 1996) composta por turistas cujo principal motivo da viagem foi turismo de negócios ou o turismo de negócios e lazer em conjunto. Considerando que a população alvo da pesquisa eram turistas de negócios, também se adotou um critério de estratificação da amostra por local de residência permanente - país e cidade de origem dos entrevistados.

Para fazer a abordagem dos turistas a serem entrevistados os pesquisadores foram localizados nas salas de embarque e check in dos dois aeroportos. Todas as pessoas que transitavam nesses locais foram abordadas, sendo o número médio de abordagens por dia de 893. Do total de pessoas abordadas somente 5,2\% resultaram em entrevistas efetivas com turistas de negócios e de lazer e negócios. Após análise do adequado preenchimento e consistência de dados obtidos através das entrevistas, a amostra total foi de 622 casos efetivos. 
A estrutura do questionário de pesquisa apresentou perguntas abertas e fechadas, com questões de múltipla escolha. As perguntas abertas foram codificadas segundo a incidência de respostas dos três primeiros dias de pesquisa e agrupadas segundo a semelhança do padrão de respostas. As perguntas fechadas foram pré-codificadas usando diversas escalas, tais como a nominal e razão para características do perfil, comportamento dos turistas e gastos de viagem; e Likert e de diferencial semântico para a avaliação dos diferentes construtos (MALHOTRA, 2006). A operacionalização dos construtos respondeu à teoria específica apresentada na seção anterior, sendo a qualidade, comprometimento e a lealdade construtos com estrutura hierárquica ou multidimensional, enquanto que os demais construtos preço, imagem, emoções, encantamento e satisfação apresentaram estrutura unidimensional. Também foi estabelecido um número mínimo de três perguntas para cada um das dimensões dos construtos multidimensionais e unidimensionais.

As principais técnicas de análise utilizadas foram a estatística descritiva, a tabulação cruzada e a intensidade da relação entre variáveis ou correlação. Não foram considerados nessas análises os valores das não-respostas e a relação simultânea entre todos os construtos do modelo da figura 1.

\subsection{Perfil e hábitos dos turistas de negócios entrevistados}

A amostra estava composta por 83,1\% homens e 16,9\% mulheres (Quadro 1). Os entrevistados têm curso superior completo $(51,4 \%)$ e pós-graduação $(33,3 \%)$; e exercem funções de gerência $(26,1 \%)$ ou ocupam cargos de direção da empresa $(19,1 \%)$. Quanto ao local de residência, destacam-se os turistas brasileiros advindos das regiões Sul (28,2\%), Sudeste $(28,0 \%)$, e Nordeste $(25,9 \%)$; e entre os estrangeiros os da Argentina (4,7\%), Uruguai (1,0\%), Estados Unidos da América e Canadá (4,5\%), Alemanha (1,9\%), Holanda (1,0\%) e Espanha (1,0\%). A maior parte dos dados do perfil dos turistas de negócios deste estudo apresentou consistência com pesquisas prévias com turistas de negócios (Canovas, 2004; Braga, 2005).

O principal motivo da viagem foi "negócios" (89,7\%), sendo que geralmente eles permanecem, em média, duas noites. Eles vieram desacompanhados $(70,2 \%)$ ou com colegas de trabalho (20,8\%). Alguns manifestaram que vieram acompanhados somente do (a) cônjuge e poucos indicaram ter vindo com filhos e amigos. A existência de acompanhantes na viagem 
apresenta pouco efeito sobre o total de gastos da viagem, sendo a média diária de, aproximadamente, R\$ 500,00 (desconsiderando desse total as despesas com transporte).

Quadro 1: Perfil dos Turistas Entrevistados

\begin{tabular}{|c|c|c|}
\hline Variável & $\mathbf{n}$ & $\%$ \\
\hline Sexo & 622 & 100,0 \\
\hline Homens & 517 & 83,1 \\
\hline Mulheres & 105 & 16,9 \\
\hline Formação & 619 & 100,0 \\
\hline Até primeiro grau & 5 & 0,8 \\
\hline Até segundo grau & 90 & 14,5 \\
\hline Superior & 318 & 51,4 \\
\hline Pós graduação & 206 & 33,3 \\
\hline Ocupação & 618 & 100,0 \\
\hline Presidente/Dono & 114 & 18,4 \\
\hline Diretor & 118 & 19,1 \\
\hline Gerente & 161 & 26,1 \\
\hline Técnico/Supervisor & 77 & 12,5 \\
\hline Assessor/Consultor & 62 & 10,0 \\
\hline Outros & 86 & 13,9 \\
\hline Local de Residência & 622 & 100,0 \\
\hline Brasil & 483 & 77,7 \\
\hline Sul & 136 & 21,9 \\
\hline Sudeste & 135 & 21,7 \\
\hline Centro Oeste & 52 & 8,4 \\
\hline Nordeste & 125 & 20,1 \\
\hline Norte & 35 & 5,6 \\
\hline Exterior & 139 & 22,3 \\
\hline América do Norte e Central & 35 & 5,5 \\
\hline América do Sul & 49 & 7,9 \\
\hline Europa & 49 & 7,9 \\
\hline Ásia/África/Oceania & 6 & 1,0 \\
\hline
\end{tabular}

$\mathrm{n}=$ Número de entrevistas válidas 
No último ano, 41,3\% dos entrevistados vieram em, até, três oportunidades à cidade. Essa freqüência tem estreita relação com o planejamento da viagem, pois aqueles advindos de destinos distantes, principalmente do exterior, planejam a sua viagem com antecedência superior a 90 dias.

As principais fontes de informação sobre a cidade são a internet $(31,9 \%)$ as agências de viagens, familiares e amigos $(23,4 \%)$. A televisão $(70,6 \%)$, revistas $(15,0 \%)$ e jornais $(7,1 \%)$ são os principais meios de divulgação de propaganda sobre a cidade, mas a mensagem transmitida não foi lembrada por $24,0 \%$ dos entrevistados. O tipo de propaganda lembrada é sobre eventos da cidade (22,9\%), a divulgada em programas de televisão $(14,9 \%)$ e informações sobre negócios $(13,9 \%)$.

\subsection{Avaliação da imagem da cidade de São Paulo}

A percepção dos turistas de negócios sobre a imagem da cidade de São Paulo foi medida a partir de dois tipos de avaliação. Na primeira, o turista indicou espontaneamente o que lhe veio à mente quando pensou em São Paulo. Essa avaliação apontou 9 dimensões, ordenadas em aspectos negativos, de 1 a 3, e positivos, de 4 a 8 . No Quadro 2, as atividades vinculadas aos negócios, trabalho e oportunidades de fechar negócios ou ganhar dinheiro foram as mais representativas da imagem da cidade $(34,6 \%)$. Também foi considerada uma "cidade grande", "moderna" e "em progresso" (13,7\%). Os aspectos negativos são: trânsito e congestionamentos $(12,1 \%)$, poluição e estresse $(9,8 \%)$. Essas impressões ressaltam a funcionalidade da cidade (CALDWELL e FREIRE, 2004).

Quadro 2: Primeira Idéia Quando se Fala na Cidade de São Paulo

\begin{tabular}{|l|r|r|}
\hline \multicolumn{1}{|c|}{ Idéia } & n & \multicolumn{1}{c|}{$\%$} \\
\hline 1. Trânsito/ Congestionamentos/ Transporte & 75 & 12,1 \\
2. Poluído/ Agitado/ Estresse/ Caos & 61 & 9,8 \\
3. Falta de segurança & 37 & 5,9 \\
4. Cultura/ Educação/ Bairros/ Paulista & 32 & 5,1 \\
5. Restaurantes/ Gastronomia & 20 & 3,2 \\
6. Compras/ Diversão/ Lazer & 16 & 2,6 \\
7. Cidade grande/ Progresso/ Moderna & 85 & 13,7 \\
8. Negócios/ Trabalho/ Novas oportunidade/ Ganhar dinheiro & 215 & 34,6 \\
9. Outras & 80 & 13,1 \\
\multicolumn{1}{|c|}{ Total } & $\mathbf{6 2 1}$ & $\mathbf{1 0 0 , 0}$ \\
\hline
\end{tabular}

$\mathrm{n}=$ Número de entrevistas válidas 
Na segunda avaliação (Quadro 3) a cidade se destaca entre as demais cidades brasileiras (92,4\%). Essa percepção não é a mesma se comparada com os destinos internacionais (61,8\%). A avaliação geral é consistente com aquela avaliação espontânea, sendo ela boa $(33,8 \%)$ e regular $(23,4 \%)$. A avaliação da imagem da cidade voltada para o segmento de negócios não necessariamente tem conotação positiva para o lazer. Kotler e outros (2006) observam que a melhoria da imagem pode transformar os elementos negativos do lugar em elementos que a diferenciem. Nesse sentido, a cidade de São Paulo, que convive com problemas de congestionamento, insegurança e poluição, destaca-se pela sua modernidade e por levar os turistas a experimentar o cotidiano.

Quadro 3: Avaliação Induzida sobre a Percepção da Imagem da Cidade

\begin{tabular}{|c|c|c|c|c|c|c|c|c|c|c|}
\hline \multirow{2}{*}{ Variáveis } & \multicolumn{7}{|c|}{ Freqüência(\%) } & \multirow{2}{*}{$\mathrm{n}$} & \multirow{2}{*}{ Média } & \multirow{2}{*}{ D.P. } \\
\hline & 1 & 2 & 3 & 4 & 5 & 6 & 7 & & & \\
\hline $\begin{array}{l}\text { São Paulo, como } \\
\text { destino de negócios, se } \\
\text { comparada com outras } \\
\text { grandes } \\
\text { brasileiras, é: }\end{array}$ & 0,2 & 0,5 & 1,3 & 5,5 & 13,0 & 30,9 & 48,5 & 598 & 6,18 & 1,024 \\
\hline $\begin{array}{l}\text { São Paulo, como } \\
\text { destino de negócios, se } \\
\text { comparada com outras } \\
\text { grandes metrópoles } \\
\text { estrangeiras, é: }\end{array}$ & 0,4 & 4,8 & 8,5 & 24,5 & 32,2 & 19,1 & 10,5 & 497 & 4,82 & 1,290 \\
\hline $\begin{array}{l}\text { A imagem geral da } \\
\text { cidade de São Paulo, } \\
\text { no contexto nacional e } \\
\text { internacional }\end{array}$ & 1,3 & 3,9 & 9,1 & 23,4 & 33,8 & 19,2 & 9,4 & 616 & 4,80 & 1,298 \\
\hline
\end{tabular}

\subsection{Qualidade}

A qualidade geral avaliada pelos turistas entrevistados considerou a experiência turística, a de negócios e a qualidade dos serviços e instalações que eles usaram na sua viajem (Quadro 4). Esses aspectos superaram as expectativas dos entrevistados $(73,4 \% ; 89,4 \%$ e $85,8 \%$, respectivamente). Essas opiniões são consistentes com a idéia de a cidade ser propícia para os negócios e possibilitar a existência de oportunidades de negócios. É importante destacar que o primeiro aspecto não foi avaliado por $24,4 \%$ dos entrevistados, pois eles não se consideram turistas e não acreditam ter realizado atividades turísticas. A avaliação dos turistas em relação 
à qualidade dos serviços é consistente com estudo da São Paulo Turismo em 2005 durante a Feira Equipotel.

Quadro 4: Análise descritiva da Variável Qualidade - Qualidade Geral

\begin{tabular}{|c|c|c|c|c|c|c|c|c|c|c|}
\hline \multirow{2}{*}{ Variáveis } & \multicolumn{7}{|c|}{ Freqüência $(\%)$} & \multirow{2}{*}{$\mathrm{n}$} & \multirow{2}{*}{ Média } & \multirow[t]{2}{*}{ D.P } \\
\hline & 1 & 2 & 3 & 4 & 5 & 6 & 7 & & & \\
\hline $\begin{array}{l}\text { Como turista, a } \\
\text { experiência ser superior. }\end{array}$ & 0,9 & 2,1 & 4,7 & 18,9 & 34,0 & 27,9 & 11,5 & 470 & 5,13 & 1,1 \\
\hline $\begin{array}{lr}\text { Como } & \text { empresário, } \\
\text { excelência } & \text { das } \\
\text { oportunidades } & \text { de } \\
\text { negócios. } & \end{array}$ & 0,3 & 0,3 & 1,7 & 8,3 & 25,4 & 38,0 & 26,0 & 603 & 5,76 & 1,0 \\
\hline $\begin{array}{l}\text { Excelência dos serviços } \\
\text { e instalações existentes } \\
\text { para facilitar a minha } \\
\text { permanência. }\end{array}$ & 0,3 & 0,5 & 2,4 & 11,0 & 27,3 & 36,7 & 21,8 & 616 & 5,62 & 1,0 \\
\hline
\end{tabular}

$1=$ Muito abaixo das expectativas; $2=$ Abaixo das expectativas; $3=$ Pouco abaixo das expectativas; $4=$ Regular; $5=$ Pouco acima das expectativas; $6=$ Acima das expectativas; $7=$ Muito acima das expectativas $\mathrm{n}=$ número de entrevistas válidas; D.P. = Desvio padrão

A qualidade geral do destino é ressaltada em relação às interações com os empresários (87,2\%). Essa expectativa não é observada em relação às interações com os residentes locais, somente $66,5 \%$ dos entrevistados manifestou estar acima das suas expectativas. Os turistas também apontaram que as interações com os funcionários dos serviços consumidos superaram suas expectativas $(85,1 \%)$.

Outro dos aspectos avaliados foi a infra-estrutura para acesso a diferentes lugares, a qual esteve pouco acima das expectativas (51,8\%). Ao julgar o acesso a diferentes lugares as pessoas se defrontam com as barreiras existentes na cidade, a principal delas os congestionamentos. Também é importante destacar que 22,2\% dos entrevistados não souberam opinar sobre a localização das atividades culturais e de lazer, provavelmente pelo pouco tempo de lazer que eles dispõem.

Os serviços prestados superaram as expectativas dos turistas $(88,5 \%)$. A boa gastronomia e a qualidade das acomodações são sempre destacadas em estudos de entidades do setor (Embratur e São Paulo Turismo). Quanto aos serviços de transporte local também foi apontado que as expectativas foram superadas $(72,7 \%)$. 
Apesar do seu grau de subjetividade, a avaliação dos resultados obtidos através da experiência mostrou que 53,7\% dos entrevistados indicaram que tiveram tempo suficiente para realizar as suas atividades rotineiras e 59,3\% perceberam que o desempenho dos serviços consumidos esteve acima do esperado, principalmente por que o desempenho não afetou a consistência da prestação dos serviços $(84,8 \%)$. Cabe destacar que o tempo de viagem na cidade pode prejudicar sua rotina $(53,4 \%)$ e que as atividades de negócios são geralmente mais lembradas do que as de lazer, quando for percebido um resultado inesperado. Finalmente, apesar de existirem funcionários capazes de garantir uma boa experiência nos serviços de acomodação e demais serviços oferecidos, há situações que não são lembradas e não causam impacto na percepção dos turistas $(17,8 \%)$.

De modo geral, os entrevistados julgaram a qualidade do destino como sendo superior às suas expectativas. No geral ele demonstra ter conhecimento da cidade e seus atrativos, da variedade gastronômica e da possibilidade de vivenciar experiências superiores nos negócios. Ele também consegue superar barreiras, como os problemas de poluição, congestionamento e insegurança.

\subsection{Preço}

A percepção dos preços praticados na cidade apresenta-se dividida, pois $45,4 \%$ consideram que eles não são inferiores aos praticados em outros destinos nacionais. Essa percepção é compartilhada por turistas nacionais e estrangeiros. A concordância quanto aos preços de outros destinos internacionais serem maiores foi $51,6 \%$, principalmente entre turistas da América do Norte e Europa. Diante da falta de um padrão de comparação, 18,6\% os turistas de negócios entrevistados não souberam opinar sobre esse aspecto.

Por outro lado, 49,2\% concordaram que o preço praticado é consistente com a qualidade dos produtos e serviços oferecidos e que esses preços estavam dentro das suas expectativas $(43,8 \%)$. Os dados mostram que o preço dos produtos e serviços provavelmente não é um balizador das suas decisões quanto à viagem ao destino (SWARBROOKE e HORNER, 2002).

\subsection{Emoções}

O sistema de coordenadas das emoções despertadas pela experiência na cidade é representado na figura 2. O sistema apresenta as emoções positivas à direita e as negativas à esquerda. Para os turistas a experiência ativou emoções positivas, principalmente quanto a ser excitante, 
encantadora e alegre. Também foi apontada como gratificante, sendo este um indicador de satisfação. A experiência foi excitante e encantadora, para os turistas da América do Norte e para a maior parte dos brasileiros, e alegre e gratificante para a maior parte dos entrevistados.

A subjetividade da relação entre emoções e a rotina na cidade influenciou a avaliação dos turistas. A localização de cada uma das reações mostra que a cidade anima as pessoas e as faz acreditar que ela pode dar ao turista uma experiência excitante e gratificante, mas ao mesmo tempo angustiante.

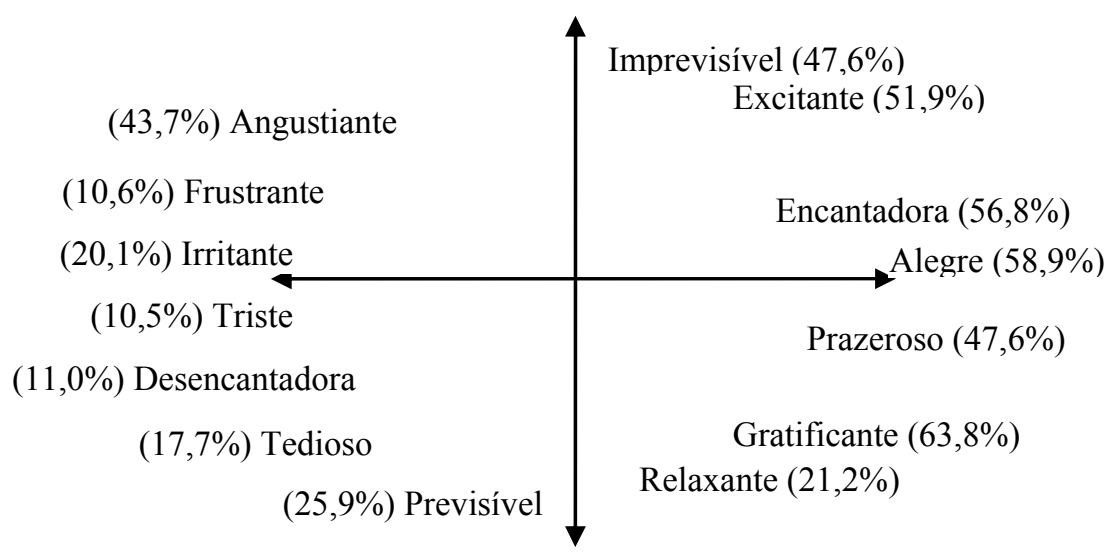

Figura 2: Adaptação do Sistema de Emoções de Russell (1980)

\subsection{Encantamento}

A opinião geral sobre o encantamento do turista em relação ao destino mostrou que $61,3 \%$ deles acreditam que a experiência foi estimulante, principalmente porque os negócios realizados atenderam suas expectativas $(75,0 \%)$. Eles também concordaram em recomendar a cidade $(60,2 \%)$, embora não necessariamente por ter recebido um serviço que estivesse além das suas expectativas (51,7\% não perceberam diferença enquanto $40,5 \%$ a perceberam) ou por perceber que houve uma preocupação na cidade por personalizar o tratamento dado aos turistas (48,3\% não perceberam alguma diferença enquanto 40,4\% a perceberam). A tabulação cruzada entre a intenção de recomendar o destino e o local de residência dos turistas mostra a maior predisposição de recomendar por parte de brasileiros, estadunidenses e canadenses. Muitos dos turistas europeus demonstraram pouca intenção de recomendar.

De maneira geral, o encantamento está mais relacionado com uma experiência estimulante para os negócios, sendo a qualidade dos serviços e o atendimento personalizado um 
complemento. Esse aspecto também estimularia a recomendação da cidade, considerando que os equipamentos turísticos favorecem a realização dos mesmos.

\subsection{Satisfação}

É importante indicar que os turistas entrevistados mostraram-se bastante satisfeitos com a maior parte dos elementos que compõe o destino, seus moradores, os serviços, os negócios e os atrativos (Quadro 5). Os turistas de negócios mostram-se satisfeitos com o comportamento dos residentes locais $(62,3 \%)$, empresários da cidade $(84,9 \%)$, com a qualidade dos produtos e serviços $(84,5 \%)$ e com diversidade de atrativos culturais e de lazer na cidade $(81,2 \%)$, embora $7,4 \%$ e $19,6 \%$ dos entrevistados, respectivamente, não tenham opinado quanto ao contato com turistas e diversidade de atrativos culturais.

Quadro 5: Análise descritiva da variável Satisfação

\begin{tabular}{|c|c|c|c|c|c|c|c|c|c|c|}
\hline \multirow{2}{*}{ Variável } & \multicolumn{7}{|c|}{ Freqüência $(\%)$} & \multirow{2}{*}{$\mathrm{n}$} & \multirow{2}{*}{ Média } & \multirow{2}{*}{ D.P. } \\
\hline & 1 & 2 & 3 & 4 & 5 & 6 & 7 & & & \\
\hline $\begin{array}{l}\text { Com o comportamento } \\
\text { dos moradores de São } \\
\text { Paulo. }\end{array}$ & 1,6 & 3,1 & 7,1 & 25,9 & 32,3 & 19,8 & 10,2 & 576 & 4,85 & 1,289 \\
\hline $\begin{array}{l}\text { Com o comportamento } \\
\text { dos empresários da } \\
\text { cidade. }\end{array}$ & 0,5 & 0,8 & 2,3 & 11,5 & 27,9 & 38,6 & 18,4 & 609 & 5,55 & 1,087 \\
\hline $\begin{array}{l}\text { Com o desempenho } \\
\text { dos serviços e produtos } \\
\text { que foram prestados e } \\
\text { vendidos. }\end{array}$ & 0,2 & 0,5 & 2,4 & 12,3 & 28,8 & 38,7 & 17,0 & 617 & 5,53 & 1,036 \\
\hline $\begin{array}{l}\text { Com a variedade de } \\
\text { atrativos turísticos } \\
\text { oferecidos. }\end{array}$ & 0,8 & 3,8 & 3,6 & 10,6 & 21,0 & 33,2 & 27,0 & 500 & 5,55 & 1,355 \\
\hline
\end{tabular}

\subsection{Comprometimento}

$\mathrm{Na}$ avaliação desta dimensão foram avaliadas três afirmações vinculadas à resistência à mudança, à avaliação dos benefícios esperados e à evocação de sentimentos. Os turistas apontaram concordância quanto à necessidade dos homens de negócios virem mais à cidade (77,0\%); a cidade ter benefícios que outras cidades brasileiras não têm (68,3\%); e a não ser feliz se não voltasse à cidade $(54,5 \%)$. Cabe destacar que as duas primeiras afirmações 
tiveram melhor concordância do que a terceira. Esse aspecto é influenciado pela subjetividade em relação aos sentimentos despertados pela cidade, assim como apontado no construto "emoções".

A primeira afirmação mostra maior concordância entre turistas brasileiros, latino-americanos e norte-americanos. Os turistas de países europeus concordam pouco com esta afirmação, talvez pela distância que tem de percorrer. Quanto a segunda e terceira afirmações, cabe destacar que os turistas dos Estados Unidos da América, Canadá, Europa e Brasil manifestaram concordância com a mesma. Em contrapartida, os turistas de países latinoamericanos ficaram divididos (aprox. 30,0\%).

Há pouca incidência de aspectos afetivos na atitude que os turistas apresentam, sendo este um fundamento de pouco impacto no estabelecimento de uma relação mais estreita com a cidade. O comprometimento é mais acentuado em relação aos negócios.

\subsection{Lealdade}

Os principais resultados do construto mostram a prioridade dada às atividades de negócios (Quadro 6). Eles têm intenção de desenvolver novos negócios, sendo uma oportunidade de conquista particular para realização de outras atividades em futuras oportunidades. Assim $86,7 \%$ dos turistas de negócios desenvolverão novas oportunidades de negócios; $67,2 \%$ virão com mais freqüência e 73,2\% acreditam ser a melhor cidade para fazer negócios.

Quadro 6: Análise descritiva da variável Lealdade

\begin{tabular}{|c|c|c|c|c|c|c|c|c|c|c|}
\hline \multirow{2}{*}{ Variável } & \multicolumn{7}{|c|}{ Freqüência (\%) } & \multirow{2}{*}{$\mathrm{n}$} & \multirow{2}{*}{ Média } & \multirow[t]{2}{*}{ D.P } \\
\hline & 1 & 2 & 3 & 4 & 5 & 6 & 7 & & & \\
\hline $\begin{array}{lr}\text { Desenvolverá novas } \\
\text { oportunidades } \\
\text { negócios na cidade. }\end{array}$ & 1,0 & 1,7 & 1,7 & 9,0 & 19,4 & 31,6 & 35,7 & 599 & 5,82 & 1,2 \\
\hline $\begin{array}{l}\text { Virá com mais } \\
\text { freqüência. }\end{array}$ & 2,5 & 6,3 & 4,3 & 19,5 & 20,5 & 22,5 & 24,2 & 599 & 5,14 & 1,5 \\
\hline $\begin{array}{llr}\text { Acreditar } & \text { ser a melhor } \\
\text { cidade para } & \text { fazer } \\
\text { negócios. } & & \\
\end{array}$ & 2,5 & 4,4 & 4,3 & 15,7 & 19,0 & 24,9 & 29,3 & 611 & 5,36 & 1,5 \\
\hline
\end{tabular}


A intenção que eles manifestam quanto a retornar à cidade é bastante elevada, considerando que o principal motivo da viagem é negócios. Os turistas costumam trazer esporadicamente seus cônjuges, filhos e amigos e, ainda, em determinadas viagens, eles vêm acompanhados por colegas. Essa intenção demonstra que o seu comportamento não estará sempre voltado a realizar negócios, representado uma oportunidade de adoção de estratégias por parte dos planejadores da cidade no sentido de cativá-los. Também é manifestada a possibilidade de recomendar e dar preferência à cidade.

\subsection{Principais inter-relações entre construtos}

As inter-relações entre construtos foram testadas a partir de correlação simples, considerando somente pares de variáveis. As correlações entre qualidade e satisfação com o ambiente empresarial $(0,506)$; imagem e lealdade em relação a ser a melhor cidade para fazer negócios $(0,406)$; emoções e encantamento, considerando que o destino é prazeroso e é um motivo para recomendá-lo a parentes e amigos (0,512); e comprometimento e lealdade, por acreditar que outros turistas de negócio devem vir mais à cidade por ser a melhor $(0,514)$, apresentaram-se significativas $(\mathrm{p}<0,05)$

As demais correlações entre construtos apresentam índices significativos, porém moderados, destacando-se a relação emoções-satisfação $(0,354)$, pois foi gratificante o contato com os empresários da cidade. A relação satisfação-lealdade não teve o comportamento esperado, embora não possa ser descartada a existência de relação entre eles (0,299). Situação parecida foi observada na relação satisfação-imagem $(0,278)$. A relação preço-satisfação foi parcialmente confirmada, considerando que o turista dificilmente possui parâmetros para avaliar os preços do destino turístico. Não foi possível obter correlação significativa entre os pares de construtos preço-lealdade; satisfação-comprometimento, imagem-comprometimento e encantamento-lealdade. Esses resultados poderão afetar a confirmação das relações simultâneas que serão testadas através de outras técnicas multivariadas, como a MES (modelagem de equações estruturais - MALHOTRA, 2006)

Os resultados apresentados indicam forte correlação entre os construtos que estimulam a lealdade do turista em relação ao destino. Por outro lado, os antecedentes, diretos e indiretos da imagem também apresentam boa correlação, o que pode favorecer a avaliação da imagem e, conseqüentemente, a lealdade do turista em relação ao destino. Assim, o principal construto que afeta a percepção da imagem de um destino é a satisfação do turista em relação a ele. A 
lealdade, representada pela intenção de retornar ou indicar o destino a amigos e parentes, está estreitamente relacionada com o comprometimento que o turista manifestou. Indiretamente, a qualidade é um antecedente importante na percepção da imagem e na intenção de se tornar leal ao destino.

\section{Considerações Finais}

Ao longo deste artigo foram descritos e analisados, com a ajuda de estatística descritiva, tabulação cruzada e indicadores de correlação os principais resultados das entrevistas com turistas de negócios que visitaram a cidade de São Paulo entre junho e julho de 2006. O tema principal era a imagem da cidade percebida por esse público alvo, sendo o objetivo principal reconhecer e entender os aspectos que influenciam a avaliação da imagem do destino turístico e a sua intenção de retornar.

A amostra pesquisada revelou a consistência do perfil de turistas de negócios com estudos locais existentes (CANOVAS, 2004; BRAGA, 2005). Também foi confirmada a relação de aspectos funcionais que imperam na imagem das cidades destinos (CALDWELL e FREIRE, 2004).

A idéia de São Paulo ser um destino de negócios é confirmada no contexto nacional e internacional. A imagem da cidade é boa, mas precisa melhorar, pois não é o principal destino internacional para fazer negócios, consistentemente com a revista América Economia (2005). Esse aspecto é complementado pela qualidade do destino, considerando que os turistas apontaram a excelência dos negócios $(89,4 \%)$. Outro aspecto complementar são os preços praticados no destino, os quais têm relação com a qualidade dos produtos e serviços consumidos pelos turistas

Também é importante destacar que o sentimento despertado pela experiência mostrou uma combinação de reações afetivas principalmente positivas (Russell, 1980), pois a cidade despertou a excitação $(51,9 \%)$, o encantamento $(56,8 \%)$ e a alegria $(58,9 \%)$ dos turistas, mas principalmente ficaram com um sentimento gratificante $(63,8 \%)$. O encantamento teve como base de avaliação o ambiente de negócios, a mesma base usada para manifestar a sua satisfação, não só como os empresários $(84,9 \%)$, mas também com os produtos e serviços oferecidos $(84,5 \%)$, atrativos $(81,2 \%)$ e residentes $(62,3 \%)$. Existe certa influência dos 
elementos afetivos, mas esta é menor comparativamente com os elementos cognitivos, consistentemente com estudo de Farias (1998). O mesmo efeito foi observado na relação entre satisfação e imagem do destino.

Diante da avaliação do desempenho, o impacto da imagem sobre o comportamento futuro dos turistas de negócios em relação ao destino justifica-se na crença de a cidade ter características próprias em relação a outras (68,3\%), principalmente para os negócios (77,0\%). Essa opinião tem origem não só na análise dos benefícios que possa alcançar ao continuar a realizar negócios, mas também quanto ao afeto desenvolvido pelos turistas em relação a ela (Oliver, 1999).

Em relação à lealdade, os turistas manifestaram que é possível desenvolver novos negócios $(86,7 \%)$ por considerar que é a melhor cidade para esse fim $(73,2 \%)$, o que é um indicador da intenção de retorno. Por outro lado, eles manifestaram seu desejo de indicar a cidade a parentes e colegas; mas, diante da existência de alternativas, pode ser que a preferência pela cidade não seja tão consistente.

Em resumo, na opinião dos turistas entrevistados prevalece a idéia de São Paulo como destino de negócios. A cidade conta com equipamentos e serviços que proporcionam comodidade e facilitam a estadia do turista, os quais são considerados de qualidade e satisfazem suas necessidades. Por outro lado, ele é leal e comprometido com o ambiente de negócios, principalmente quando ele indica a cidade a amigos e parentes. A imagem é um dos aspectos que reforça a lealdade do turista em relação ao destino e a relação qualidade-satisfação favorece a avaliação da imagem e lealdade; contudo, a comunicação da imagem precisa ser melhorada, pois o turista pretende indicar o destino.

\section{Referências Bibliográficas}

AAKER, Jennifer; FOURNIER, Susan; BRASEL, S. Adam. 2004. When good brands do bad. Journal of Consumer Research, v.31, n.1, p.1-15.

AHMED, Zafar. 1991. The influence of the components of a state's tourist image on product positioning strategy. Tourism Management, v. 12, n.4, p.331-340, dezembro.

AMÉRICA ECONOMIA. 2005. Especial ciudades 2005: las mejores ciudades para hacer negocios. Maio, p.31. 
ANDREASSEN, Tor W; LINDESTAD, Bodil. 1998. Customer loyalty and complex services: the impact of corporate image on quality, customer satisfaction and loyalty for customer with varying degrees of service expertise. International Journal of Service Industry Management, v.9, n.1, p.7-23.

AUH, Seigyoung; JONHSON, Michael. 2005. Compatibility effects in evaluations of satisfaction and loyalty. Journal of Economic Psychology, v.26, n.1, p.35-57.

BALOGLU, Seyhmus; McCLEARY, Ken W. 1999. A model of destination image formation. Annals of tourism research, v. 26, n. 4, p.868-897.

BAPTISTA, Paulo. 2005. Lealdade do consumidor e os seus antecedentes: um estudo aplicado ao setor varejista na internet. Tese (Doutorado). Departamento de Administração. Faculdade de Economia, Administração e Contabilidade da USP. São Paulo, 180p.

BEI, Lien-Ti; CHIAO, Yu-Ching. 2001. An integrated model for the effects of perceived product, perceived service quality and perceived price fairness on consumer satisfaction and loyalty. Journal of Consumer Satisfaction, Dissatisfaction and Complaining behavior, v.14, p.125-140.

BENDAPUDI, Neeli; BERRY, Leonard. 1997. Customers' motivations for maintaining relationships with service providers. Journal of Retailing, v.73, n.1, p.15-37.

BIGNÉ, J. Enrique; SÁNCHEZ, M. Isabel; SANCHEZ, Javier. 2001. Tourism image, evaluation variables and after purchase behavior: inter-relationship. Tourism Management, v.22, n.6, p.607-616.

BITNER, Mary. 1992. Servicescapes: the impact of physical surroundings on customers and employees. Journal of Marketing, v.56, n.2, p.57-71, abril.

BOLTON, Ruth; DREW, James. 1991. A multistage model of customers' assessments of service quality and value. Journal of Consumer Research, v.17, n.4, p.375-384, março.

BRADY, Michael; CRONIN, Joseph. 2001. Some new thoughts on conceptualizing perceived service quality: a hierarchical approach. Journal of Marketing, v.65, n.3, p.34-49, julho.

BRAGA, Debora. 2005. À margem das ferias de negócios: uso do tempo livre do turista em São Paulo. Tese (Doutorado). Escola de Comunicações e Artes. Universidade de São Paulo, São Paulo, $161 \mathrm{p}$.

BRAMWELL, Bill; RAWDING, Liz. 1996. Tourism marketing images of industrial cities. Annals of tourism Research, v.23, n.1, p.201-221.

BROWN, James; LUSCH, Robert; NICHOLSON, Carolyn. 1995. Power and relationship commitment: their impact on marketing channel member performance. Journal of Retailing, v.71, n.4, p.363-392.

CALDWELL, Nial; FREIRE, João. 2004. The differences between branding a country, a region and a city: applying the brand box model. Journal of Brand Management, v.12, n.1, p.50-61, setembro.

CANOVAS, Maria. 2004. O turismo de negócios e o consume cultural e de lazer na cidade de Salvador: motivações e atitudes. Tese (Doutorado). Escola de Comunicações e Artes. Universidade de São Paulo, São Paulo, 185p.

CHI, Gengqing. 2005. A study of developing destination loyalty model. Tese (Doutorado). Environmental Science Graduate Program. Oklahoma State University. Oklahoma, 229p.

CHURCHILL, Gilbert; SURPRENANT, Carol. 1982. An investigation into the determinants of customer satisfaction. Journal of Marketing Research, v.19, n.4, p.491-504, novembro. 
CRONIN, Joseph; TAYLOR, Steve. 1992. Measuring service quality: a reexamination and extension. Journal of Marketing, v.56, n.3, p.55-68, julho.

DERBAIX, Christian; PHAM, Michel. 1991. Affective reactions to consumption situations: a pilot investigation. Journal of Economic Psychology, v.12, n.2, p.325-355.

ECHTNER, Charlotte; RITCHIE, J.R. Brent. 2003. The meaning and measurement of destination image. The Journal of Tourism Studies, v.14, n.1, p.37-47, maio.

EMBRATUR - Instituto Brasileiro de Turismo. 2003. Estudo da demanda turística internacional 2002. Brasília: Embratur.

ENGEL, James; BLACKWELL, Roger; MINIARD, Paul. 2000. Comportamento do consumidor. Rio de Janeiro: Livros Técnicos e Científicos Ed., 641p.

FARIAS, Salomão. 1998. Avaliação simultânea dos determinantes da satisfação do consumidor : um estudo no segmento da terceira idade. Tese (Doutorado). Departamento de Administração. Faculdade de Economia, Administração e Contabilidade da USP. São Paulo, 218p.

FORNELL, Claes et al. 1996. The American customer satisfaction index: mature, purpose, and findings. Journal of Marketing, v.60, n.4, p.7-18, outubro.

FORNELL, Claes; JOHNSON, Michael. 1993. Differentiation as a basis for explaining customer satisfaction across industries. Journal of Economic Psychology, v.14, n.4, p.681-696.

FOURNIER, Susan. 1998. Consumers and their brands: developing relationship theory in consumer research. Journal of Consumer Research, v.24, n.4, p.343-372.

FYALL, Alan; CALLOD, Christine; EDWARDS, Brenda. 2003. Relationship marketing: the challenge for destinations. Annals of Tourism Research, v.30, n.3, p.644-659.

GALLARZA, Martina; SAURA, Irene; GARCÍA, Haydée. 2002. Destination image: toward a conceptual framework. Annals of tourism research, v. 29, n. 1, p.56-78.

GEVA, Aviva; GOLDMAN, Arieh. 1991. Duality in consumer post-purchase attitude. Journal of Economic Psychology, v.12, n.1, pp.141-164.

GRÖNROOS, Christian. 1990. Service management and marketing: managing the moment of truth in service competition. Massachusetts: Lexington Books, 298p.

HEUNG, Vincent; CHENG, Eliza. 2000. Assessing tourists' satisfaction with shopping in the Hong Kong special administrative region of China. Journal of Travel Research, v.38, n.4, p.396-404.

IZARD, Carroll. 1991. The psychology of emotions. New York: Plenum Press, 451p.

IWASAKI, Yoshiro; HAVITZ, Mark E. 1998. A path analytic model of the relationships between involvement, psychological commitment and loyalty. Journal of Leisure Research, v.30, n.2, p.256280.

JENKINS, Olivia. 1999. Understanding and measuring tourist destination images. International Journal of Tourism Research, v.1, n.1, p.1-15.

JENSEN, Jan. 2004. The application of Herzberg's two-factor theory to the realm of tourist attractions. In: Proceedings of the New Zealand Tourism and Hospitality Research Conference 2004. Smith, K. e Chuta, C. (Eds.). Wellington, 8 a 10 de dezembro, pp.180-190. Disponível em: www.vms.vuw.ac.nz/vuw/fca/vms/files/aa39.pdf., Acesso em: 08/06/2005. 
JOHNSON, Michael et al. 2001. The evolution and future of national customer satisfaction index models. Journal of Economic Psychology, v.22, n.2, p.217-245.

KELLER, Kevin. 1993. Conceptualizing, measuring, and managing customer-based brand equity. Journal of Marketing, v.57, n.1, p.1-22, janeiro.

KOTLER. Philip et al. 2006. Marketing de lugares: como conquistar crescimento de longo prazo na América Latina e no Caribe. São Paulo: Prentice Hall, 340p.

KUMAR, Anand; OLSHAVSKY, Richard; KING, Maryon. 2001. Exploring alternative antecedents of customer delight. Journal of Consumer Satisfaction, dissatisfaction and complaining behavior, v.14, p. 14-26.

LEE, Gyehee. 2001. Constructs of tourists' destination loyalty and market segmentation. Tese (Doutorado). Department of Hospitality and Tourism Management. Purdue University, Indiana, 191p.

LEE, Joohyun. 2003. Examining the antecedents of loyalty in a forest setting: relationship among service quality, satisfaction, activity involvement, place attachment and destination loyalty. Tese (Doutorado). College of Health and Human Development. Leisure Studies. The Pennsylvania State University, Pennsylvania, 168p.

LIVESEY, Frank. 1978. Formação de preço. São Paulo: Saraiva, 150p.

MALHOTRA, Naresh. 2006. Pesquisa de marketing: uma orientação aplicada. Porto Alegre: Bookman, 720p.

MARCONI, Marina, LAKATOS, Eva. 1996. Técnicas de pesquisa: planejamento e execução de pesquisas, amostragens e técnicas de pesquisa, elaboração, análise e interpretação de dados. São Paulo: Atlas, 231p.

MARTÍNEZ-TUR, Vicente; CABALLER, Amparo; TORDERA, Nuria. 1996. Evaluación de la calidad de servicio en hostelería. Estudios Turísticos, n.130, p.71-85.

NORMANN, Richard. 1984. Service management. New York: John Wiley \& Sons, 143p.

O'LEARY, Sinéad; DEEGAN, Jim. 2005. Ireland's image as a tourism destination in France: attribute importance and performance. Journal of Travel Research, v.43, n.3, p.247-256, fevereiro.

OLIVER, Richard. 1980. A cognitive model of the antecedents and consequences of satisfaction decisions. Journal of Marketing Research, v.27, n.4, p.460-469, novembro.

1999. Whence consumer loyalty? Journal of Marketing, v.63, special issue, p.33-44.

; RUST, Roland; VARKI, Sajeev. 1997. Customer delight: foundations, findings, and managerial insight. Journal of Retailing, v.73, n.3, p.311-336.

OPPERMANN, Martin. 2000. Tourism destination loyalty. Journal of Travel Research, v39, v.1, p.78-84, agosto.

PARASURAMAN, A.; ZEITHAML, Valerie; BERRY, Leonard. 1994. Reassessment of expectations as a comparison standard in measuring service quality: implications of further research. Journal of Marketing, v.58, n.1, p.111-124, janeiro.

PETRICK, James. 2004. First Timers' and Repeaters' Perceived Value. Journal of Travel Research, v.43, n.1, p.29-38, agosto. 
PIKE, Steven; RYAN, Chris. 2004. Destination positioning analysis through a comparison of cognitive, affective, and conative perceptions. Journal of Travel Research, n.42, n.4, p.333-342, maio.

RIDDLE, Dorothy. 1999. Business tourism: niches for developing countries. International trade forum, n.3, p. 4-10.

RODRIGUES, Joab. 2004. Gestão da satisfação e da fidelização de consumidores: um estudo dos fatores que afetam a satisfação e fidelização dos consumidores na área de turismo. Anais XXVIII Encontro Nacional de Cursos de Pós Graduação em Administração, Curitiba, Paraná, (anais eletrônicos).

RUSSELL, James. 1980. A circumplex model of affect. Journal of personality and social psychology, v.39, n.6, p.1161-1178.

SIRGY, M. Joseph; SU, Chenting. 2000. Destination image, self-congruity, and travel behavior: toward and integrative model. Journal of Travel Research, v.38, n.4, p.340-352, maio.

SPTURIS - São Paulo Turismo, Coordenadoria de Informação e Pesquisa. Pesquisa sobre o perfil do público da Equipotel 2005. Setembro de 2005. Disponível em: http://www.cidadedesaopaulo.com/pre_rel_equipotel2005.pdf. Acesso em 30/12/05

SWARBROOKE, John; HORNER, Susan. 2002. O comportamento do consumidor no turismo. São Paulo: Aleph, 405p.

TAYLOR, Steven; BAKER, 1994. Thomas. An assessment of the relationship between service quality and customer satisfaction in the formation of consumers' purchase intentions. Journal of Retailing, v.70, n.2, p.163-178.

WESTBROOK, Robert. 1987. Product/consumption-based affective responses and postpurchase processes. Journal of Marketing Research, v.24, n.3, p.258-270, agosto.

WOODSIDE, Arc; FREY, Lisa.; DALY, Robert. 1989. Linking service quality, customer satisfaction, and behavioral intention. Journal of Health Care Marketing, v.9, n.4, p. 5-17, dezembro.

ZEITHAML, Valerie; BERRY, Leonard; PARASURAMAN, A. 1993. The nature and determinants of customer expectations of service. Journal of the Academy of Marketing Science, v.21, n.1, p.1-12.

\section{Recebido em: 15/11/2006 (1 ${ }^{\text {a }}$ versão) 15/01/2007 ( $2^{\mathrm{a}}$ versão) Aprovado em: 30/06/2007}

